The Version of Record of this manuscript has been published and is available in ARCHITECTURAL

\title{
Evaluating the efficiency of membrane's refurbishment solutions to perform vertical extensions in old buildings using a multicriteria decision-support model
}

Mónica Macieira* ${ }^{\mathrm{a} *}$, Paulo Mendonça ${ }^{\mathrm{a}}$, João Miranda Guedes ${ }^{\mathrm{b}}$ and Anabela

Tereso $^{\mathrm{c}}$

${ }^{a}$ School of Architecture/LAB2PT, University of Minho, Campus Azurém, 4800-058

Guimarães, Portugal; e-mail - mendonca@arquitetura.uminho.pt;

${ }^{b}$ Faculty of Civil Engineering/CONSTRUCT, University of Porto, Rua Dr. Roberto Frias, 4200-465 Porto, Portugal; e-mail-jguedes@fe.up.pt;

${ }^{c}$ School of Engineering, Production and Systems Department/Centre ALGORITMI, University of Minho, Campus Azurém, 4800-058 Guimarães, Portugal; e-mail anabelat@dps.uminho.pt

* Corresponding author:

Mailing address: School of Architecture/ Lab2PT, University of Minho, Campus de Azurém, 4800-058 Guimarães, Portugal;

Tel.: +351 253510534;

Fax: +351253510509 ;

Mobile phone: +351963350928 ;

E-mail: mrfmacieira@gmail.com 


\section{Abstract}

The initial premise of this research is that the relative efficiency of refurbishment solutions with architectural membranes needs to be measured in order to allow its comparison with conventional solutions, helping decision makers to select the most efficient solutions. The evaluation of this efficiency depends on economic features, but also on functional, technological and environmental ones. This study presents a model to solve this problem, using decision trees, multicriteria decision-making methods (SAW and AHP) and a sensitivity analysis. The selection of the criteria and the assignment of the corresponding weights was attained through an expert group survey for a baseline scenario, aiming maximizing functional performance (such as energy savings) and minimizing employed resources (materials, costs, etc.). The most efficient refurbishment solution among the set of alternatives was reached using the developed model. The methodology was applied to a case study - an old building from the 19th century, located in Portugal, which was refurbished with a vertical extension. The result reveals that the proposed model is successful and illustrates the potential of this evaluation methodology to compare and quantify the efficiency of a series of different lightweight constructive solutions. It also underlines the advantages of using lightweight building technologies, especially with architectural membrane materials, in building refurbishments.

Keywords: multicriteria decision-support model; efficiency; vertical extensions; architectural membrane materials; refurbishment.

\section{Introduction}

Due to growing limitations on land use and sustainability issues consciousness, the building rehabilitation market has faced growing opportunities around the world. With the increasing local and global migration seeking better opportunities in cities, the current urban agendas have put forward compact city concept as a promising solution towards sustainable urban development. Vertical extension to existing buildings is considered an approach towards increasing cities' density. However, rehabilitation projects are usually characterized by high levels of uncertainty and risk, due to the lack 
of information and the complexity of the operations (Lee \& Gilleard, 2002). The decision-making process to select the best solution involves a wide range of divergent interests, including constructive (i.e. planimetric and volumetric changes, assembly time), functional/social/cultural (i.e. the improvement of architectural and aesthetic appearance and indoor comfort), economic, environmental aspects, etc. In particular, the increasing importance given today to the environmental compatibility leads designers to combine both the use of energy efficient materials and technical solutions to maximize savings. Thus, alternative solutions to conventional ones must be studied, especially when the costs and weight of refurbishment constructive solution are inhibiting factors (for owners, designers, investors and different parties involved). The available lightweight constructive systems to improve functional building's performance (energy efficiency and interior comfort) are already numerous and, therefore, identifying the most appropriate rehabilitation options is a topic of great importance, considering the possible costs and other aspects involved. For instance, architectural membrane building technologies are interesting alternatives in cases where the use of conventional/traditional building options is limited, especially for its weight (Macieira, Mendonça \& Guedes, 2017).

Therefore, decision makers need decision support tools to help choosing the most advantageous option. The analysis of alternative refurbishment solutions is usually performed considering economic, environmental, technical, technological, comfort, among other aspects. Ideally, the efficiency level of rehabilitation solutions, configured in an evaluation model, should include criteria that allow the decision maker to perform a comprehensive analysis of the available alternatives, defining criteria's goals maximize or minimize, in order to make a proper choice. 
This research intends to evaluate, first, in what measure multicriteria evaluation models can be used to support refurbishment decision-making and, second, if membrane solutions can constitute an efficient alternative to conventional extensions solutions which represent $68 \%$ of the 2015 refurbishment works in Portugal (INE, 2017) - in particular when it comes to add storeys to older buildings with structural limitations. For this, an old building from the 19th century, located in Porto (Portugal), was used as case study. A set of 6 lightweight solutions were studied to be applied to the building and a multicriteria evaluation model was adopted to support decision-making, namely to select the most efficient option, determining its relative efficiency. The results present a new outcome for the state of the art of lightweight design/building applications field.

The case study and the multicriteria proposed model are described in the following sections (from section 2 till 7).

\subsection{Overview of decision support tools for refurbishment}

In order to design and implement an efficient building refurbishment, it is necessary to carry out an exhaustive search of solutions that may be applied. The efficiency level of a building refurbishment depends on a large number of factors. There has been a large development of models and methods used by different authors to support the best refurbishment measures under different perspectives i.e. that consider multiple criteria. These methodologies can be categorized into two main approaches: the models in which alternative refurbishment solutions are explicitly known a priori and the models in which alternative refurbishment solutions are implicitly defined in the setting of an optimization model (Asadi et al., 2014). The most common a priori approach is one in which the decision maker assigns weights to each criterion, and the weighted sum of the criteria makes it possible to find the best design solution. 
A large number of decision support tools were identified by Ferreira, Pinheiro and Brito (2013) research, covering 40 decision support tools for building's refurbishment (including relevant Portuguese tools). Their research shows that environment and the economy are the most assessed areas. Social/society is mentioned less, and the main criteria assessed are related to thermal comfort.

Decision support systems for building's refurbishment can also be classified according to their methodologies: offline or on-line approaches (Ferreira et al., 2013). Offline approach constitutes a discrete decision problem (when a finite and not too wide group of alternatives is assessed) and on-line approaches use modern control systems connected via web to optimize the systems energy and the indoor comfort in real time building's operation.

Based on an analysis of offline decision support systems for the refurbishment of buildings, some examples can be found, such as: (a) a multicriteria "knapsack" model proposed by Alanne (2004) to help designers to select the most feasible renovation actions in the conceptual phase of a renovation project; (b) a novel assessment method that evaluates the real energy and economic savings of refurbishment actions, depending on different energy-related occupant scenarios, to enable comparisons with other buildings (Serrano-Jimenez et al., 2019); (c) a methodology to optimize combining artificial neural networks and life cycle cost (Almeida \& De Freitas, 2016); (d) a multi-criteria assessment methodology for the environmental, economic and social evaluation of different residential energy refurbishment solutions, based on effectiveness indices (Lizana et al., 2016).

Based on an analysis of on-line systems, some examples can also be found, such as: (a) BeSmart2 application (Tereso \& Amorim, 2015) (developed in C\#, it implements the AHP, SMART and Value Functions methods) that allows comparisons between 
several alternatives with several criteria, always keeping a permanent backup of both model and results, and provides a framework to incorporate new methods in the future; (b) XENIOS methodology and software (Dascalaki \& Balaras, 2004) to assess refurbishment scenarios in hotels, permitting users to perform a preliminary audit and make a first assessment of cost-effective energy efficient renovation practices; (c) a multicriteria decision support system for construction (Kaklauskas et al., 2007); (d) MultiOpt decision support tool, a genetic algorithm (NSGA-II) coupled to TRNSYS and economic and environmental databases for the optimization of renovation operations based on existing assessment software and methods, was developed by Chantrelle et al. (2011); (e) Interactive Data Flow (IDF) system that takes advantage of Building Information Modelling (BIM), Building Energy Modelling (BEM) and Analytical Hierarchy Process (AHP) techniques, to focus on main clients' building refurbishment needs - using them together, enhances the decision process and provides data to set up a strategic refurbishment plan (Tronchin, Manfrean \& Tagliabue, 2016). Antipova et al. (2014) present a systematic tool for the optimal refurbishment of buildings based on a rigorous mixed-integer linear program (MILP) by means of Life Cycle Assessment (LCA) principles, which allow evaluating the impact of each alternative being assessed considering all the stages in its life cycle; it identifies, in a systematic manner, the best alternatives for reducing the environmental impact of buildings. The capabilities of this approach were illustrated using a case study from Portugal.

Regarding the selection of vertical/rooftop extension building technologies, few studies are found. Dind, Lufkin and Rey (2018) presents a multicriteria evaluation of the architectural concept to design timber construction systems for vertical extensions of office buildings. According to Amer and Attia (2019), the selection of optimum roof 
stacking construction method is merely based on subjective evidence supported on architects' or owners' requirements. Therefore, they identified, categorized and ranked 37 influential criteria behind the selection and decision making on roof stacking methods, based on sustainability triple bottom line, i.e. environmental, economic and social, using AHP technique. An intensive literature review and pilot surveys, to architects and building engineers, have been carried out. The outcomes of this research draw the line to develop a new tool that facilitates the construction of sustainable roofs in European cities.

From the literature review, it can be oberserved that Multicriteria Criteria Decision Methods (MCDM) gain popularity in the selection process of refurbishment solutions. However, studies about selection of building solutions for rooftop extensions are recent and still limited. To overcome this limitation, authors propose to apply a methodology for selecting vertical extensions/rooftop building technologies for old buildings.

\section{Case study}

The old building taken as case study (Figure 1a) presents a constructive system with characteristics similar to the majority of the houses built in Porto, Portugal, during the 19th century: single-leaf granite walls with lime and granitic sand-based mortar; timber floor structures; wooden window frames with single glass $(3 \mathrm{~mm})$; light timber frame partition walls; plaster ceilings and sloping roof with timber structure and ceramic tiles. The top horizontal slab that will serve as support for the vertical extension is made of a timber structure, too. In the last 10 years, the building suffered significant degradation; the lack of maintenance allowed water to enter inside the building, causing deterioration of the wooden structure of the roof and the top slab. Because of it, there was the need to demolish both the roof and the slab and perform a new rooftop extension. Figure $1 \mathrm{~b}$ 
presents the refurbishment project by the design office Anarchlab (2017), which considers timber structural elements.

[Figure 1 near here]

\subsection{Lightweight building solutions for rooftop extensions}

The building case-study was used to evaluate and compare the efficiency of several lightweight vertical extension's options, namely those presented in Figure 2, which include conventional reference models using timber or steel (CWood and CSteel), and proposed alternative solutions using membranes (Alternative Membrane base (AMb), namely: Alternative Membrane variant $1(\mathrm{AMv} 1)$, variant 2 (AMv2) and variant 3 $(\mathrm{AMv} 3))$. Because vertical extensions correspond to an increase of weight to the existing structure, it is important that they are conceived with lightweight structures, in particular when they are meant to be misaligned from the lower contour walls, i.e. from the main load bearing walls. The next sections refer to the characteristics of the lightweight vertical extension options that were analysed in this research and applied to the case study.

\subsubsection{Existent Traditional building Solution (Traditional Solution - TS).}

The original building presents a small rooftop extension volume, traditionally called "mirante" in Portuguese (Figure 1a and 2 - TS). It is made of exterior and interior lightweight framed timber walls (exterior ones covered with corrugated metal sheet from the outside and with lime and sand-based plaster from the inside), a timber ceiling and a roof timber structure covered with ceramic tiles.

\subsubsection{Conventional refurbishment building solutions}

The solution with Wood structures (Conventional Wood - CWood) considers the refurbishment using a conventional wood building solution (wood framing and OSB 
(Oriented Strand Board) panels) (Figure 1b and Figure 2). The exterior envelope is made of a ceramic tiles roof supported by a timber structure; the walls are covered with corrugated metal sheet on the outside and have internal thermal insulation and OSB in the middle, and plasterboard in the inner side (Table 4).

The solution with Steel structures (Conventional Steel - CSteel) is a variant of the CWood solution. It has the same exterior envelope, but covering an LSF (Light Steel Framing) structure, i.e. using cold-formed galvanized steel profiles (Figure 2 and $3)$.

\subsubsection{Alternative Membrane refurbishment building solutions (Alternative Membrane - AM)}

The alternative solutions correspond to the use of membrane materials in the construction system. Membranes are textile composite or foil materials that present low self-weight (approx. $1 \mathrm{~kg} / \mathrm{m}^{2}$ ), high flexibility and resistance under tensile forces. In this study, a modular and prefabricated constructive solution AMb(ase) is proposed. However, as $\mathrm{AMb}$ is lightweight and, therefore, has reduced thermal mass, three variants, AMv1, AMv2 and AMv3 are proposed to overcome this limitation, namely by adding materials with phase change and/or vegetation that take advantage of the thermal mass of the building itself. All AM present a modular multilayer envelope system, with membranes in both sides (with low emissivity and self-cleaning coating, combined with a thermal/acoustic insulation material), an insulated core and a wood structure with modular and prefabricated elements (frames) connected with metal tubes, cables and fittings. All these elements can be easily transported manually and are assembled in situ (Figure 2).

[Figure 2 near here] 


\section{Framework of the proposed multicriteria decision model}

The literature shows that multicriteria methods have been used as a methodological approach to improve the decision process when choosing refurbishment solutions.

Decision support models are developed from a constructivist paradigm where the participants in the decision-making process discover together the problem and obtain the model that best meets the group interests (Ribeiro \& Tereso, 2016).

The proposed decision model, schematically shown in Figure 3, is deterministic - it considers all variables to be known. Furthermore, as the decision problem (to select the most efficient lightweight vertical extension solution for old buildings) involves the consideration of several criteria, it becomes complex, requiring the definition of a multicriteria decision model. In this type of models, usually, it is not possible to find an alternative that is better than the others in all criteria, simultaneously. Therefore, it is necessary the intervention of the decision maker to reach a conclusion, by combining its preferences with the criteria considered for the various alternatives. In fact, multicriteria problems do not objectively have an optimal solution. There is only a preferred solution, which can vary for different decision makers, depending on the importance given to each criterion.

The study of a problem within the generic Multi Criteria Decision Analysis (MCDA) approach includes three main phases: structuring, evaluation and recommendations, which constantly interact with each other (Clemen \& Reilly, 2001). The implementation of the MCDA is a non-linear process comprising several steps. The steps can be summarized as follows (Clemen \& Reilly, 2001): (1) identify the problem/objective, decision makers and criteria; (2) identify alternatives; (3) decompose and model the problem; (4) choose the best alternatives; (5) perform sensitivity analysis and; (6) give recommendations for the implementation of the chosen alternatives. 
The development of a model to support the decision of selecting the most efficient vertical extension option can be similar for different refurbishment's problems and stakeholders, but it has to be adapted to each case.

\section{Proposed multicriteria decision model}

In the present research, a multicriteria framework was used as the methodological approach to the refurbishment choice process of the most efficient vertical extension. Briefly, the structure of the proposed decision model is presented in Figure 3 and some details about its implementation are explained in the following sections. Based on the previous mentioned steps 1 to 6 , considering the specificity of this research problem, steps i to viii (Figure 3) were identified. The problem implementation is performed in a tripartite hierarchical way (Figure 3). The first hierarchical level consists in the decision problem definition and decision makers' identification. The second hierarchical level corresponds to criteria definition and the third to the definition of alternatives.

[Figure 3 near here]

According to the classification proposed by Ferreira, Pinheiro and Brito (2013), for decision support systems (DSS) of building's refurbishment, the proposed model constitutes an offline combined approach of a discrete decision problem (a finite group of alternatives is assessed) with a simulation-based approach (SMB), as it uses simulation models to calculate each solution's performance value.

When looking for the most environmentally beneficial solution, apart from the operational phase, it is also important to consider the embodied impacts at end-of-life. According to Ferreira, Pinheiro and Brito (2013) DSS's classification in relation to their life cycle approach, the present decision model can be considered a Life Cycle Analysis 
(LCA)-based model, because it includes criteria associated with environmental and economic impact, in all life cycle phases, as presented in section 7.

It is expected that the proposed model will be a basis to support future refurbishment decision making evaluations, involving vertical extensions. In the case studied, the decision maker evaluates 30 items (criteria) from different vertical extension's options (alternatives), as presented in section 7.

\subsection{Methods/techniques used to support decision-making}

MCDM problems involve the evaluation and combination of two or more criteria, in order to classify, order or choose one among other available alternatives. In this research, based on a multicriteria approach, it was built, tested and validated a decision support model to determine the relative efficiency of available alternatives to functional refurbishments interventions. This model incorporates the AHP and Simple Additive Weighting (SAW) method. AHP and SAW have been selected because are simple, robust, repeatable, objective, commonly recognized as valid and eventually they have been used in many different researches in the construction industry (Zanakis, Solomon, Wishart \& Dublish, 1998; Zheng, Jing, Huang, Shi \& Zhang, 2010). According to Tupenaite et al. (2010) these methods allow considering the relative importance of the several criteria, by a decision group, in order to select the alternative that presents the best (major) global value. In the following sections, the adopted steps in this procedure are explained in detail, using as example the selected case study.

The MCDM, together with the AHP and SAW methods, has been used first to evaluate the criteria importance and after to pick the most suitable option, in which the whole process of the present research is outlined. 


\section{Step i: Decision problem definition}

The decision problem consists in selecting the best alternative - constructive solution for functional refurbishment interventions, with vertical extensions, of old buildings, in accordance with the criteria presented in Figure 4. These criteria were defined and discussed by the decision-making group, aiming to define the aspects on which the relative efficiency of functional refurbishment options should be measured (covering economic, social/aesthetics/patrimonial, constructive, security, functional and environmental aspects). To aid the choice of criteria to assess the options under consideration, it was considered the set of guidelines developed by Saaty (1980). Based on this and on literature review, the decision group agreed to select the 30 quantitative and qualitative decision criteria.

The AHP hierarchy of criteria decomposes the refurbishment problem at hand into sub-problems (criteria), which are decomposed into sub-problems and so on, until the problem is represented as a decision tree of criteria (Figure 4).

[Figure 4 near here]

\section{Step ii: Decision makers identification}

The decision makers were responsible for the criteria selection and its weight assignment. The decision group is composed by: 1 building physics specialist; 1 structural engineering specialist and 1 architecture technician. Ideally, the decision group size should be larger, but in this case, it is only composed by 3 elements, because: (1) it is difficult to find a large number of available experts to do pairwise comparisons and (2), at same time, that know well the alternatives under analysis. However, in future works, the weight assignment can be updated in relation to the decision makers specific needs. Moreover, this weight list can be used in other related case studies, even if one or 
more parameters are excluded from the evaluation, without the need to redo the pairwise comparison, if specialists have similar preferences.

\section{Step iii: Criteria definition and hierarchical structure}

Criteria are tools that allow the comparison of various actions and alternatives in relation to the decision makers points of view. To make pairwise comparison, it is recommended that the number of the criteria be between three and seven, never exceeding nine, so that the result is coherent and not too extensive (Saaty, 1990). The criteria definition process was established by the decision group.

In the next steps, AHP and SAW methods are applied. To do this, first, it is necessary to define all the criteria and priority levels. Table 1 presents the 7 selected criteria, which corresponds in total to 12 quantitative subcriteria and 18 qualitative subcriteria. The later ones are related with future community support frameworks, such as climate change adaptation, risk prevention/management, environmental impact reduction and efficient use of resources.

[Table 1 near here]

In order to speed up the performance evaluation of the six refurbishment projects, according to the selected quantitative criteria, a BIM of the building was created and used for quantities extraction, and as the starting point for a BEM used for estimating energy demands of the building in the six refurbishment scenarios. All criteria are evaluated for each refurbishment options project. The quantitative subcriteria, associated to functional, constructive and environmental aspects were measured through calculations with computer tools such as Design Builder® and One Click LCA ${ }^{\circledR}$. The quantitative parameters associated to economic aspects were evaluated by consulting several databases, material suppliers, installers, etc. Only the cost associated with the end of life (recycling, landfill, etc.) was not considered in this 
study for two reasons: (1) enormous uncertainty in its calculation and; (2) expected reduced influence on total cost, meaning that its inclusion in the evaluation was not expected to provide results that were more accurate.

For the qualitative subcriteria, the assessment was made by a score obtained from aggregation of judgments of a decision group, and associated to descriptions and evaluation scales, as presented in Table 2.

[Table 2 near here]

\section{Step iv: Obtaining priority vector - assigning weights to criteria and subcriteria}

Ideally, it is considered appropriate to adopt a weighting system able to consider the relative importance of the criteria. Otherwise, all criteria would have the same importance, which does not correspond to the reality. Therefore, a pairwise comparison (inserted into AHP decision-making method) was made between the elements of the second hierarchical decision-support level. One of the most and widely applied method to derive criteria weights in multiple criteria analysis is AHP (Saaty, 1980). AHP is becoming quite popular in research due to the fact that its utility outweighs other methods (Cheng \& Li, 2001). This method is proposed to be used in determining the weights of the criteria in this research; Tupenaite et al. (2010) algorithm is partially used (Figure 5).

[Figure 5 near here]

A very important issue in this research is the selection of decision makers; they should have appropriate knowledge about the alternatives under analysis, as well as experience in rehabilitation projects. As mentioned at section 6 , three experts fully satisfied the 
requirements and participated on a survey. The questionnaires, consisting of judgment matrices, were prepared and provided to experts.

To perform this pairwise comparison, a scale is required for normalization. Comparisons were made by the decision-making group, using the Saaty (1990) fundamental scale, which ranges from 1 to 9. Pairwise comparisons were made only among criteria and subcriteria (shown in Table 1), regarding the decision problem. It was made by a survey form - with Transparent Choice AHP tool (2018) - composed by 1 pairwise matrix (for the 7 criteria) and 7 pairwise matrices (for the subcriteria of each criteria group). Then, the eigenvector method was employed to obtain the local priority vectors for the coupled comparison matrix (i.e. the weight for each criterion). The consistency of a pairwise comparison was tested applying the consistency ratio (CR). If the CR is less than 0.1, the pairwise comparison is considered acceptable (Saaty, 1980). According to this, the CR of these judgments was positively checked. Then, the collected judgments were aggregated, in a process involving their geometric mean, through which the local and global weight (the relative importance) of each criterion and subcriterion was calculated; the weighting/relative importance of each criterion and subcriterion was obtained individually (for each decision group element) and aggregated by the "Aggregation of Individual Judgments" (AIJ) technique, according to Forman and Peniwati (1998).

The obtained results are presented at Table 3. It shows that the decision-making group attributed greater importance to functional aspects (C6), whose weight is $30 \%$, among which stands out the building operational energy consumption in 60 years $(47 \%$ local weight and $14 \%$ of overall weight). Criterion C4 (safety aspects) is weighted with $22 \%$, and criterion $\mathrm{C} 1$ (economic aspects) with $15 \%$.

[Table 3 near here] 


\section{Step v: Alternatives}

Alternatives correspond to the available vertical (rooftop) extension options among which decision-maker can choose from. In summary, alternatives under analysis correspond to the constructive solutions presented in Table 4. Knowing that ultra heavy exterior envelope elements (walls and roof) present more than $500 \mathrm{~kg} / \mathrm{m}^{2}$, heavy elements between 250 and $500 \mathrm{~kg} / \mathrm{m}^{2}$ and lightweight elements between 100 and 250 $\mathrm{kg} / \mathrm{m}^{2}$ (Mendonça \& Bragança, 2007), one may consider that building elements with membrane technologies, as those proposed in this study, which weight less than $100 \mathrm{~kg} / \mathrm{m}^{2}$ (Table 4), are ultra lightweight solutions. Thus, the relative efficiency evaluation performed in this study compares lightweight conventional constructive solutions with ultra lightweight alternative ones (Table 4), through a multicriteria model implementation. All alternatives presented at Table 4 have the same U-value.

[Table 4 near here]

\section{Step vi: Criteria normalization and multicriteria evaluation}

After criteria and subcriteria weight assignment, the next step is to aggregate the score values over the entire set of criteria into a single score number, indicating the total utility caused by each refurbishment alternative. The use of a simple additive weighting function allows translating all criteria into a global value. The method used to solve this problem is referred as Simple Additive Weighting (SAW) method; a method of wide use where the final score is the result of the weighted sum of various criteria, namely by using a common numerical scale. Therefore, the general formula for the calculation of the scores in this method is:

$$
V_{i}=\sum_{F=1}^{n} w_{j} r_{i j}
$$

$$
\begin{aligned}
& V_{i}-\text { overall score for option } i ; \\
& w_{j}-\text { weight of criterion } j ; \\
& r_{i j}-\text { score of option } i \text { on criterion } j \text {; } \\
& n-\text { number of criteria. }
\end{aligned}
$$


The score for each criterion under analysis (Table 3) was used to evaluate the weighted sum of the formula. To aggregate all criteria, it is necessary a scale conversion. The global scale used was a scale from 0 to 1 ( 0 being the worst and 1 the best). Considering that the objective is to minimize (equation 2) or maximize (equation 3 ), the functions used to convert criteria values into the scale 0 to 1 were the following:

$$
\begin{aligned}
& V(C)=\frac{(C \max -C)}{(C \max -C M m)} \\
& V(C)=\frac{(C-C M \min )}{(C M a x-C M i n)}
\end{aligned}
$$

where $\mathrm{Cmax}$ is the criterion maximum value; $\mathrm{C}$ is the criterion under evaluation; $\mathrm{Cmin}$ the criterion minimum value.

The evaluation of different criteria with different units of measure and magnitude requires normalization. Criteria normalization aims: (1) avoiding scale effects in aggregating different criteria indicators and (2) solving the problem of some criteria being of the type "the bigger the better" and others "the bigger the worse". This process is effective because it normalizes the criteria by assigning them the value 1 for the best solution and 0 for the worst; it simplifies the whole selection process, avoiding errors and confusions. In this step, all values associated to each alternative, previously normalized according to the maximizing or minimizing function, must be multiplied by their global weight. Then, these values were modelled using a decision tree (Figure 6), where the best alternative will get the highest score. The computer tool, used to implement the model, was the Precision Tree, an add-in to Microsoft Office Excel, from Palisade Decision Tools (2018).

Depending on the refurbishment stakeholders, the criteria weight assignment (priority vector) can be different, so a sensitivity analysis was made and presented in section 11 . 
In this baseline decision-making scenario (Table 3), and after the application of SAW method (Table 5), it is concluded that alternative A4 (AM v1) is the most relevant to solve the decision problem (Figure 6), while alternative A2 (CSteel) is the least relevant.

[Table 5 near here]

[Figure 6 near here]

\section{Step vii: Sensivity analysis}

In the present study, the method adopted for the sensitivity analysis consists of a simulation with uniform criteria weigt distribution over multiple cycles. In each cycle, one fixed criterion varies in a range of $0 \%$ to $100 \%$ from the base value, in steps of $10 \%$ (as exemplified in Table 6) - each variation corresponds to a scenario. The procedure is as follows: each criterion is selected and its weight value is changed, creating a total of 77 weighting scenarios, as presented at Table 7. For example, in $\mathrm{C} 1$ cycle, $\mathrm{C} 1$ criterion's weight range between 0 to $100 \%$, while the remaining criteria present equal remaining weight; so, if $\mathrm{C} 1$ weight $=\mathrm{X} \%, \mathrm{C} 2=\mathrm{C} 3=\mathrm{C} 4=\mathrm{C} 5=\mathrm{C} 6=\mathrm{C} 7=(100-\mathrm{X}) \% / 6$.

[Table 6 near here]

[Table 7 near here]

The efficiency of an alternative should be relative to the best option. To measure the efficiency of the worst option over the best, the smaller of the two is determined and the mean is calculated; if this average is low, it means that on average there is little efficiency of the second option in relation to the first one. So, the efficiency percentage for each alternative is obtained through equation (4). Table 7 presents the results and Figure 7 presents graphics with the efficiency variation of each alternative per cycle scenario, in relation to criteria weight variation. 


$$
\text { Ax Efficiency } \text { Cy }_{y}=\frac{\overline{A x \%}}{A x \max }
$$

where $\mathrm{Ax}$ is the alternative under evaluation for a $\mathrm{Cy}$ cycle; $\mathrm{Ax} \%$ is the weighted and normalized alternative; Ax max is the best alternative of the considered Cy scenario.

The application of this procedure shows that A4 alternative - AMv1 - is more efficient (being the dominant in scenarios majority) while A2 alternative - CSteel - is the least efficient. In 77 iterations, alternative A4 presents and average efficiency of 93\%, being $\mathrm{A} 4>\mathrm{A} 5>\mathrm{A} 6>\mathrm{A} 3>\mathrm{A} 1>\mathrm{A} 2$. Considering all weight variations for all criteria, the alternative A4 - AMv1 - is, on average, $1 \%$ to $45 \%$ better than the other solutions (A5 and $\mathrm{A} 2$ respectively).

[Figure 7 near here]

The results in Table 7 indicate that A4 alternative (AMv1) maintains its efficiency as the functional aspects weight increases, up to $50 \%$; from $70 \%$, A6 alternative (AMv3 - which has a vegetable membrane material in the exterior envelope) becomes the most efficient alternative. This last alternative contributes to: energy needs reduction (through thermal building insulation); urban heat islands mitigation and partial replacement of vegetation that has been destroyed to build the existing building. In addition, it has other benefits, such as: pollution levels reduction; carbon dioxide sequestration, particularly in urban environments, so GWP parameter is the lowest when compared to other alternatives; acoustic insulation increases and membrane material longevity increase: 30 years instead 15 for common membrane.

Figure 7 shows graphical results of the sensitivity analysis carried out for each criterion considered. It can be found that A4 alternative (AMv1 - with 93\% efficiency), together with A5 alternative, (AMv2 - with 92\%) are the dominant alternatives in most weight range scenarios for each criterion. However, when C3 criterion - aesthetic aspects - presents a $60 \%$ weight, A4 alternative is no longer the chosen one, becoming 
A1 (CWood - conventional wood structure solution) the best one. When criteria C6 (functional aspects) and C7 (environmental impact aspects) presents a weight of $70 \%$, A6 alternative (AMv3) become the preferred one.

\section{Step viii: results discussion and recommendations}

This last step concerns the identification of aspects that can improve the performance of the selected alternative. Figure 7 points out that aesthetic (C3) and security $(\mathrm{C} 4)$ aspects of Membranes Alternatives (A3, A4, A5 and A6) need to be improved in order to achieve a better overall performance, especially when it achieves an assigned weight above $30 \%$.

Analyzing the results obtained with the application of this multicriteria decisionsupport model, according to the sample and analyzed criteria, one can verify that the most efficient refurbishment solution for the vertical extension is the A4 alternative AMv1 - Alternative refurbishment solution using membrane materials, version 1. AMv1 presents, for most of the analyzed criteria, better performance than the considered reference solutions. The final order (from worst to best) was: A2 (CSteel) $<$ A1 $($ CWood $)<$ A3 $($ AMb $)<$ A6 (AMv3) < A5 (AMv2) < A4 (AMv1).

Thus, the less efficient alternative is A2 (CSteel) - conventional refurbishment building solution using Steel structures. Conventional A1 (CWood) and A2 (CSteel) alternatives proved to be less effective than Membrane alternatives (A3, A4, A5 and A6) due to all analysed criteria, except C3 (>30\%) and C4 (>40\%). Conventional building technologies present good aesthetic and security efficiency, but require a more rational use of materials to achieve good efficiency level on the remaining criteria.

In summary, the relative efficiency of alternative membrane solutions (AMs) ranges from $45 \%$ to $20 \%$ (best and worst option, respectively), i.e. are $45 \%$ to $20 \%$ more efficient than conventional reference solutions (CSWood and CSteel). 
When it comes to refurbishment intervention with vertical extensions, all stakeholders involved in the rehabilitation process, such as architects and engineers, should pay particular attention to functional, economic and security aspects, because these criteria received the highest levels of priority in the efficiency evaluation.

\section{Conclusions}

The purpose of this research was to evaluate the relative efficiency of refurbishment actions with architectural membrane technologies, in comparison with conventional ones. To solve this problem, as there are several criteria to be analysed, a multicriteria decision-support model was used.

The decision model was built using the AHP technique to prioritize and select the most relevant criteria (with a decision group of experts) and the SAW method, converting all criteira values in a scale from 0 to 1 , using a maximization or a minimization linear function, later combined with weights, to obtain the overall value of each refurbishment alternative. The sensitivity analysis carried out allowed evaluating the robustness of the created model, as it evaluates the weight variation's impact of each criterion in the final decision. Thus, it made possible to calculate the allowable variation ranges of weight's values for each criterion in order to determine which is the dominant/most efficient alternative.

This research concludes that alternative membrane options constitute an efficient alternative to conventional ones for building refurbishment's scenarios with vertical extensions.

Despite the benefits of the adopted multricriteria techniques (AHP and SAW) such as flexibility, consistency and ease of understanding - their application is timeconsuming. At AHP classification, the difficulty increases as the number of parameters to be pairwise compared increases. 
Notwithstanding the complexity of this decision support model, it allows future stakeholders to speed up the process of evaluating different refurbishment alternatives for vertical extensions. The expectation of the present research is that the proposed multicriteria evaluation model could be used in different refurbishment scenarios. It serves as a basis for future evaluations, with the possibility to change criteria weights, as weights assigning can be updated in relation to specific decision-maker needs.

As Internet and technology are in constant development, online systems will become increasingly relevant. Thus, in future works, developed methodologies can be simplifyed and translated to one interface user, expecting to be online - a simple tool that can be easily obtained and used by stakeholders; applications can be developed to make the connection between the developed model and a refurbishment system decision making software, not only for a portuguese context (as the present case study), but also for other countries or climate contexts. Improvements can be also made in the proposed model, by adding some input links from BIM, BEM, LCA and other models or databases, to flexiblize and speed up the decision process.

In reality, this work can be seen as a first version of a database. Despite this research being more focused in functional, economic, environmental, social and constructive criteria, in further developments, this database can be increased with more criteria, such as quantitative structural performance ones, in order to complete the efficiency evaluation scenario. Turning this evaluation model into an online tool (such BeSmart2 application (Tereso \& Amorim, 2015)) would make it easier: to redo the evaluation, considering other cases; to add more evaluation steps, criteria, subcriteria and alternatives to compare it with membrane alternatives, increasing confidence in membrane efficiency solutions. 


\section{Disclosure statement}

No potential conflict of interest was reported by the authors.

\section{Acknowledgments/ funding}

This research was made possible by the support of the: Portuguese Foundation for Science and Technology (FCT), Portuguese Ministry of Education and Science (MCE) and European Social Fund (ESF) with the reference grant SFRH/BD/104891/2014; the Project UID/AUR/04509/2013 by FCTMEC by national funding and FEDER co-financing under the new PT2020 partnership agreement - Lab2PT, School of Architecture/ University of Minho, Portugal; and Project POCI-01-0145-FEDER-007457 - CONSTRUCT - Institute of R\&D In Structures and Construction of Faculty of Engineering/ University of Porto, Portugal, funded by FEDER funds through COMPETE2020. Authors also thanks to: owners of the building case study and Anarchlab architecture firm for provide the case study building's designs. Also, thanks to Bionova Ltd for provide a One Click LCA student's license.

\section{References}

Alanne, K. (2004). Selection of renovation actions using multi-criteria \&quot;knapsack\&quot; model. Automation in Construction, 13(3), 377-391.

Almeida, R. \& Freitas, V. (2016). An insulation thickness optimization methodology for school buildings rehabilitation combining artifcial neural networks and life cycle cost. Journal of Civil Engineering and Management, 22(7), 915-923.

Amer, M. \& Attia, S. (2019). Identification of sustainable criteria for decision-making on roof stacking construction method. Sustainable Cities and Society, 47, 101456.

Anarchlab. (2017). Pinheiro - Anarchlab Arquitectura, Lda. Retrieved March 8, 2019, from http://www.anarchlab.pt/albums/categories/obras/pinheiro/

Antipova, E., Boer, D., Guillén-Gosálbez, G., Cabeza, L. \& Jiménez, L. (2014). Multiobjective optimization coupled with life cycle assessment for retrofitting buildings. Energy and Buildings 82, 92-99.

Asadi, E., da Silva, M., Antunes, C., Dias, L. \& Glicksman, L. (2014). Multi-objective optimization for building retroft: A model using genetic algorithm and artifcial neural network and an application, Energy and Buildings 81, 444-456.

Chantrelle, F., Lahmidi, H., Keilholz, W., Mankibi, M. \& Michel, P. (2011). Development of a multicriteria tool for optimizing the renovation of buildings. Applied Energy 88, 1386-1394.

Cheng, E. W. L. \& Li, H. (2001). Analytic hierarchy process. Measuring Business Excellence, 5(3), 30-37. 
Clemen, R. \& Reilly, T. (2001). Making hard decisions with DecisionTools (2nd rev.). [Pacific Grove, CA] Duxbury Thomson Learning.

Dascalaki, E. \& Balaras, C. A. (2004). XENIOS — a methodology for assessing refurbishment scenarios and the potential of application of RES and RUE in hotels. Energy and Buildings, 36(11), 1091-1105.

Dind, A., Lufkin, S. \& Rey, E. (2018). A Modular Timber Construction System for the Sustainable Vertical Extension of Office Buildings. Designs 2018, 2, 30.

Ferreira, J., Duarte Pinheiro, M. \& de Brito, J. (2013). Refurbishment decision support tools: A review from a Portuguese user's perspective. Construction and Building Materials, 49, 425-447.

Ferreira, J., Pinheiro, M. D. \& Brito, J. de. (2013). Refurbishment decision support tools review-Energy and life cycle as key aspects to sustainable refurbishment projects. Energy Policy, 62, 1453-1460.

Forman, E. \& Peniwati, K. (1998). Aggregating individual judgments and priorities with the analytic hierarchy process. European Journal of Operational Research, 108(1), 165-169.

INE (2017). Estatísticas da Construção e Habitação - 2016. Retrieved March 8, 2019, from

https://www.ine.pt/xportal/xmain?xpid=ine\&xpgid=ine_publicacoes\&publicacoesp ub_boui $=277046703 \&$ publicacoesmodo $=2$

Kaklauskas, A., Zavadskas, E. K. \& Trinkunas, V. (2007). A multiple criteria decision support on-line system for construction. Engineering Applications of Artificial Intelligence, 20(2), 163-175.

Lizana, J., Barrios-Padura, A., Molina-Huelva, M. \& Chacartegui, R. (2016). Multicriteria assessment for the effective decision management in residential energy retrofitting. Energy and Buildings 129, 284-307.

Lee, Y. \& Gilleard, J. (2002). Collaborative design: a process model for refurbishment. Automation in Construction, 11(5), 535-544.

Macieira, M., Mendonça, P. \& Guedes, J. M. (2017). Architectural membranes on building's functional refurbishment. IOP Conference Series: Materials Science and Engineering, 264(1), 012005.

Mendonça, P. \& Bragança, L. (2007). Sustainable housing with mixedweight strategyA case study. Building and Environment, 42(9), 3432-3443.

Palisade. (2018). PrecisionTree. Palisade. Retrieved from https://www.palisade.com/precisiontree/

Rey, E. (2004). Office building retrofitting strategies: multicriteria approach of an architectural and technical issue. Energy and Buildings, 36(4), 367-372.

Ribeiro, E. \& Tereso, A. P. (2016). The application of a decision model in the 
management of raw material costs. ICOPEV 2016 - 3rd International Conference on Project Evaluation, 53-59. Retrieved from

http://repositorium.sdum.uminho.pt/handle/1822/43674

Saaty, T. L. (1980). The analytic hierarchy process : planning, priority setting, resource allocation. McGraw-Hill International Book Co. Retrieved from https://books.google.pt/books/about/The_Analytic_Hierarchy_Process.html?id=Xx i7AAAAIAAJ\&redir_esc $=y$

Saaty, T. L. (1990). How to make a decision: The analytic hierarchy process. European Journal of Operational Research, 48(1), 9-26.

Serrano-Jimenez, A., Lizana, J. \& Molina-Huelva, M. (2019). Decision-support method for profitable residential energy retrofitting based on energy-related occupant behaviour. Journal of Cleaner Production 222, 622-632.

Šiožinytė, E., Antuchevičienè, J. \& Kutut, V. 2014. Upgrading the old vernacular building to contemporary norms: multiple criteria approach, Journal of Civil Engineering and Management 20(2), 291-298.

Tereso, A. \& Amorim, J. (2015). BeSmart2: A Multicriteria Decision Aid Application (701-710), Springer, Cham. https://doi.org/10.1007/978-3-319-16486-1_69

Transparent Choice. (2018). AHP Software - Decision Making Tools, Transparent Choice. Transparent Choice. Retrieved from https://www.transparentchoice.com/ahp-software

Tronchin L., Manfren M. \& Tagliabue L.C. (2016). Optimization of building energy performance by means of multi-scale analysis - Lessons learned from case studies. Sustainable Cities and Society, 27, 296-306.

Tupenaite, L., Zavadskas, E. K., Kaklauskas, A., Turskis, Z. \& Seniut, M. (2010). Multiple criteria assessment of alternatives for built and human environment renovation. Journal of Civil Engineering and Management, 16(2), 257-266.

Zanakis, S. H., Solomon, A., Wishart, N. \& Dublish, S. (1998). Multi-attribute decision making: A simulation comparison of select methods. European Journal of Operational Research, 107(3), 507-529.

Zheng, G., Jing, Y., Huang, H., Shi, G. \& Zhang, X. (2010). Developing a fuzzy analytic hierarchical process model for building energy conservation assessment. Renewable Energy, 35(1), 78-87. 


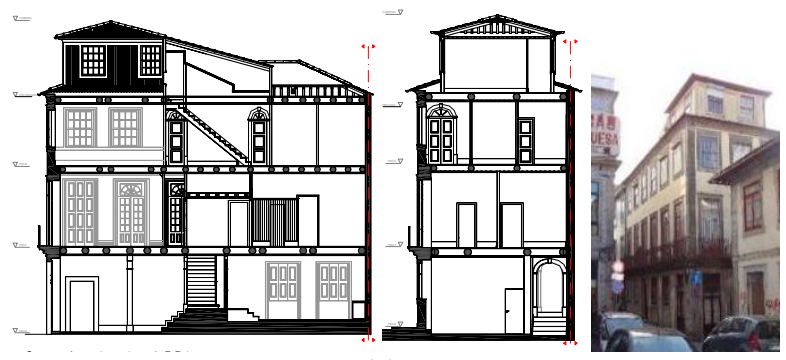

(a)
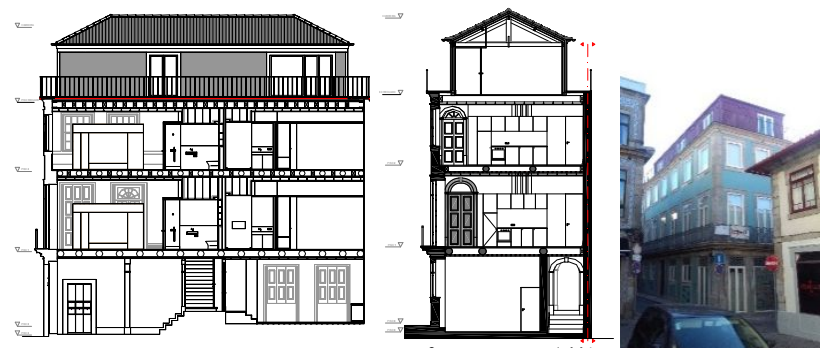

(b)

Figure 1. Sections and exterior view of the building case study: (a) in its original state and (b) with the adopted refurbishment project using timber structures (designed by Anarchlab (2017)).

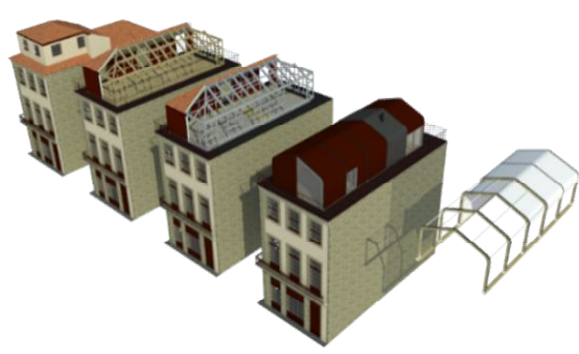

Existent TS
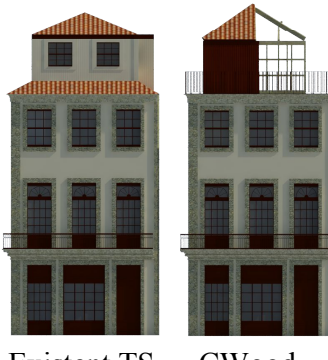

CWood

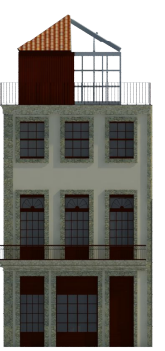

CSteelt

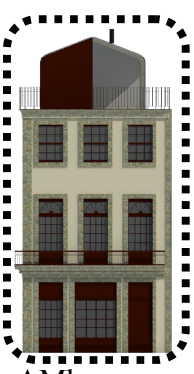

$\mathrm{AMb}$

Figure 2. Axonometric (left) and front (right) virtual views of the case study with the different rooftop options considered. 


\begin{tabular}{|c|c|}
\hline $\begin{array}{l}\text { Step i: Decision object/problem definition } \\
\text { Select the best building technology option (alternatives) to realize a refurbishment intervention with a } \\
\text { vertical extension, in an old building, located at an urban city centre - Porto city, Portugal. }\end{array}$ & \multirow[b]{2}{*}{$\begin{array}{c}1^{\text {st }} \\
\text { level }\end{array}$} \\
\hline $\begin{array}{c}\text { Step i: Decision-makers identification } \\
\text { Decision-making group composed by: } 1 \text { expert in building physics and architecture; } 1 \text { expert in structural } \\
\text { engineering with experience in rehabilitation projects; } 1 \text { architecture technician. }\end{array}$ & \\
\hline \multicolumn{2}{|l|}{ 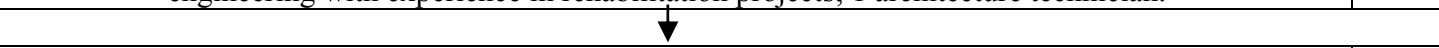 } \\
\hline $\begin{array}{l}\text { Step iii: Criteria definition and hierarchical structure } \\
\text { Adoption of the AHP pairwise comparison technique + verification of individual judgments consistency } \\
\text { (using Transparent Choice } \AA \text { tool }(2018) \text { ). Qualitative criteria obtained through AHP surveys and } \\
\text { quantitative criteria obtained through numerical simulations based on a BIM of the building case study - } \\
\text { used for quantities extraction for constructive, economic and environmental impact criteria and as the } \\
\text { starting point for a BEM. }\end{array}$ & \multirow[t]{2}{*}{$\begin{array}{c}2^{\text {nd }} \\
\text { level }\end{array}$} \\
\hline $\begin{array}{c}\text { Step iv: Obtaining the priority vector - assigning weights to criteria and subcriteria - base scenario } \\
\text { The weighting/relative importance of each criterion and sub criterion is obtained individually, for each } \\
\text { element of the group and aggregated by "Aggregation of Individual Judgments" (AIJ) technique, } \\
\text { according Forman and Peniwati (1998). }\end{array}$ & \\
\hline $\begin{array}{c}\downarrow \\
\text { Step v: Alternatives definition } \\
\text { CWood; CSteel; AMb; AMv1; AMv2; AMv3. } \\
\end{array}$ & $\begin{array}{c}3^{\text {rd }} \\
\text { level }\end{array}$ \\
\hline \begin{tabular}{c}
\multicolumn{1}{|c|}{ Step vi: Select the best alternatives } \\
Implementation of the Simple Additive Weighting (SAW) method.
\end{tabular} & \\
\hline $\begin{array}{c}\text { Step vii: Sensitivity analysis } \\
\text { Simulation with uniform criteria's weight distribution over multiple cycles. }\end{array}$ & \\
\hline $\begin{array}{l}\downarrow \\
\text { Step viii: Recommendations }\end{array}$ & \\
\hline
\end{tabular}

Figure 3. Flowchart of the adopted decision analysis process in the present case study (adapted from Clemen and Reilly (2001)).

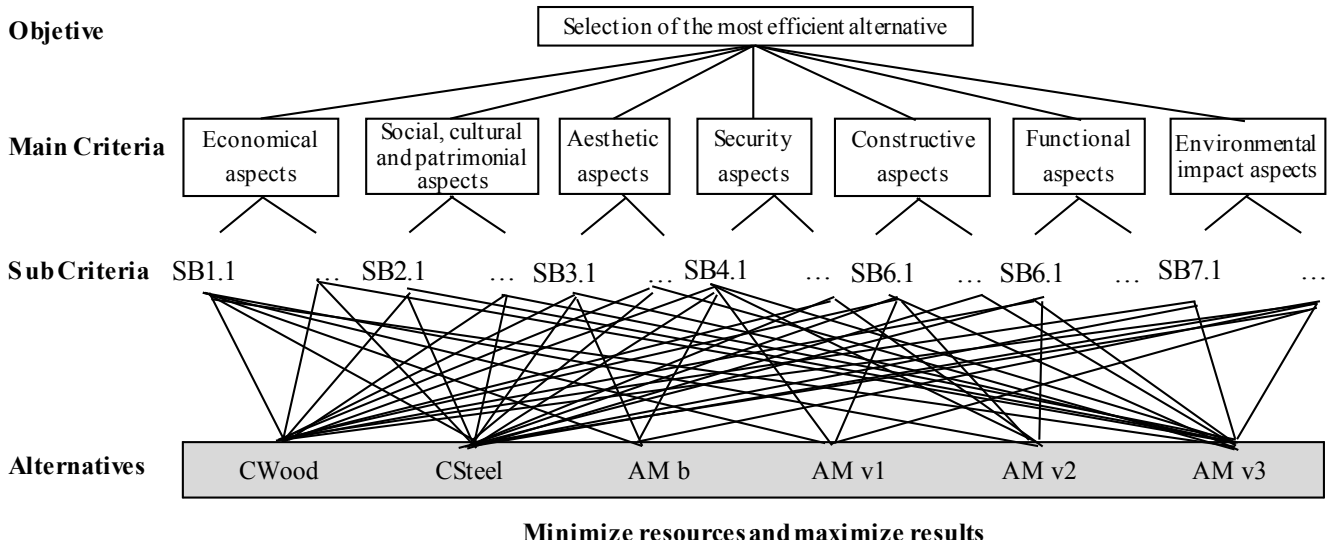

Figure 4. Hierarchical AHP structure for selecting the best (most efficient) constructive solution for a refurbishment intervention with a vertical extension. 


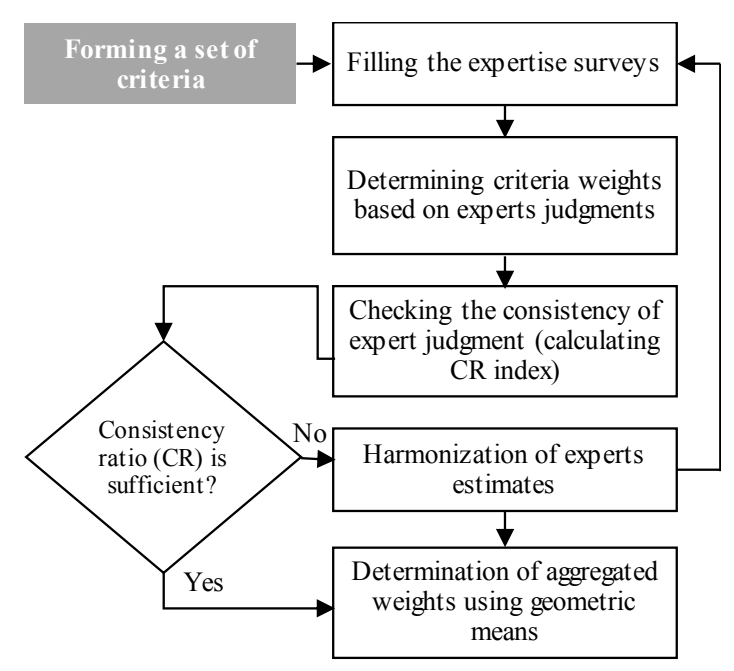

Figure 5. Algorithm for determination of criteria's weights by pairwise comparison (adapted from Tupenaite et al. (2010)).

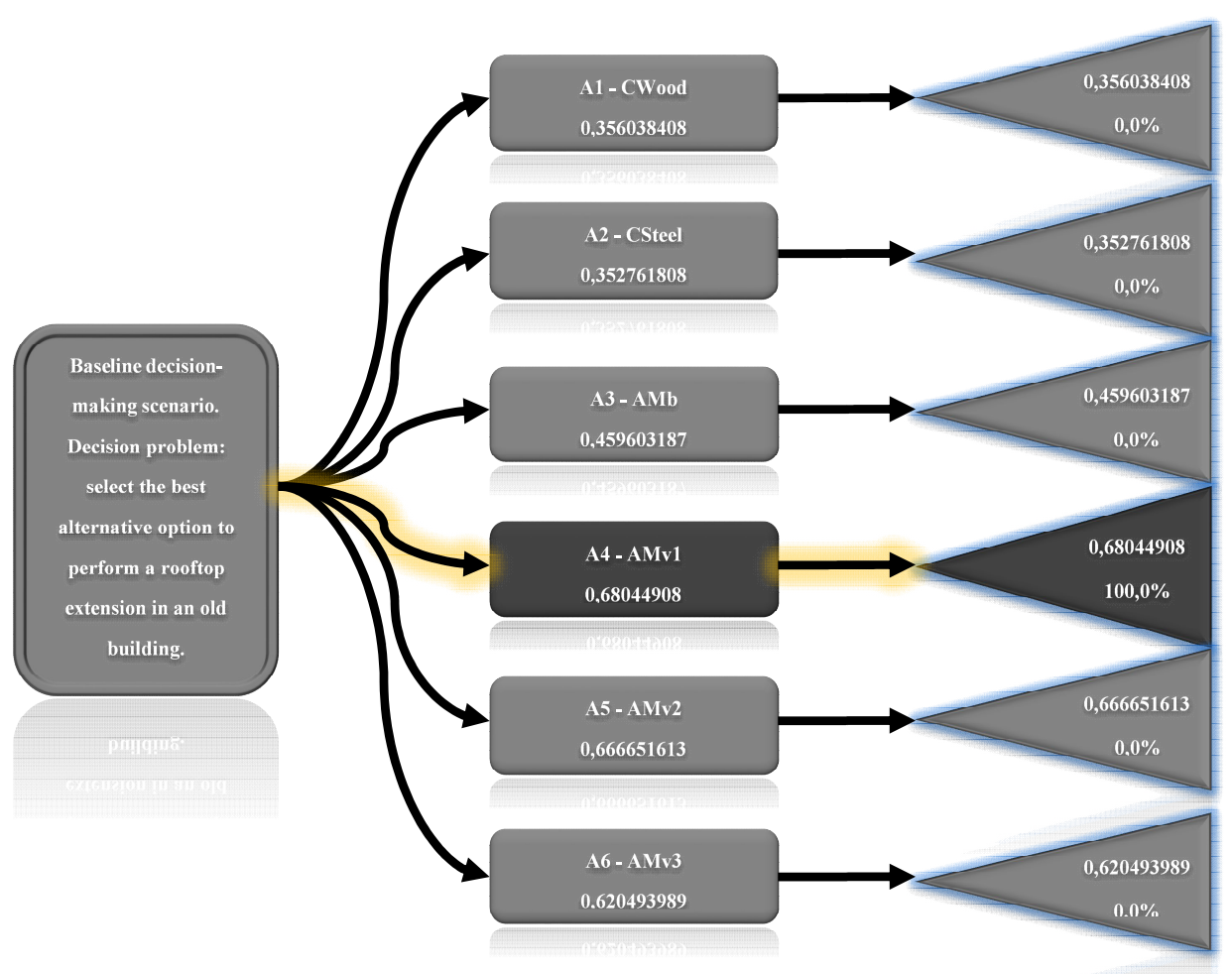

Figure 6. Decision tree to solve the case study decision problem "choose the best vertical extension option for an old building". Chart obtained by Precision Tree application from Palisade (2018) 

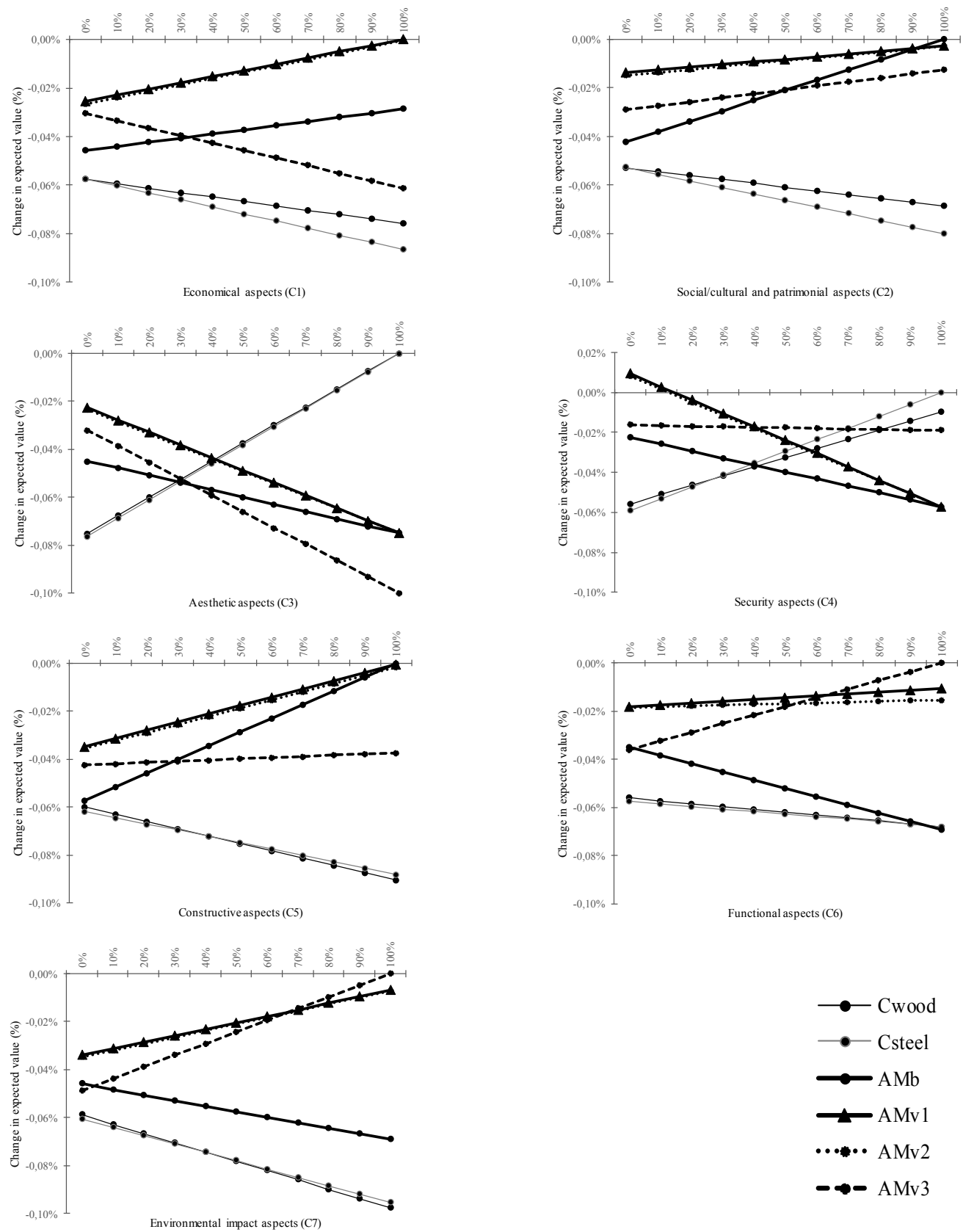

Figure 7. Expected efficiency values for each alternative under analysis according to individual variation of each criterion. 
Table 11. Hierarchical decision problem structure - to consider at criteria weight assignment (using AHP method) and multicriteria evaluation (using SAW method).

\begin{tabular}{|c|c|c|c|c|c|c|c|}
\hline \multicolumn{8}{|c|}{$\begin{array}{l}\text { LEVEL } 1 \text { - Decision problem } \\
\begin{array}{c}\text { Select the best building technology option (alternatives) to realize a refurbishment intervention with a vertical extension, in an old } \\
\text { building, located at an urban city centre - Porto city, Portugal. }\end{array}\end{array}$} \\
\hline \multicolumn{8}{|c|}{ LEVEL 2 - criteria and subcriteria } \\
\hline No. & Criteria & No. & Code & Subcriteria & Type & Objective & Indicator \\
\hline \multirow{4}{*}{ C1 } & \multirow{4}{*}{$\begin{array}{l}\text { Economic } \\
\text { aspects }\end{array}$} & 1 & $\mathrm{SC} 1.1$ & Construction cost. & QN & min. & $€$ \\
\hline & & 2 & $\mathrm{SC} 1.2$ & Operational energy cost (heating and cooling for 60 years). & $\mathrm{QN}$ & $\min$. & $€$ \\
\hline & & 3 & $\mathrm{SC} 1.3$ & Maintenance cost (60 years). & QN & $\min$. & $€$ \\
\hline & & 4 & $\mathrm{SC} 1.4$ & $\begin{array}{l}\text { Payback period of investment in vertical extension design } \\
\text { option. }\end{array}$ & QN & $\min$. & years \\
\hline \multirow{4}{*}{$\mathbf{C 2}$} & \multirow{4}{*}{$\begin{array}{l}\text { Social, cultural } \\
\text { and } \\
\text { patrimonial } \\
\text { aspects }\end{array}$} & 5 & $\mathrm{SC} 2.1$ & Use of traditional building materials and techniques. & QL & Max. & 0 a 5 \\
\hline & & 6 & $\mathrm{SC} 2.2$ & Ability to install in occupied sites. & QL & Max. & 0 a 5 \\
\hline & & 7 & $\mathrm{SC} 2.3$ & Degree of intrusiveness. & QL & $\min$. & 0 a 5 \\
\hline & & 8 & $\mathrm{SC} 2.4$ & Impact of the constructive process on the neighbourhood. & QL & $\min$. & 0 a 5 \\
\hline C3 & $\begin{array}{l}\text { Aesthetic } \\
\text { aspects }\end{array}$ & 9 & $\mathrm{SC} 3.1$ & Aesthetic quality of intervention form exterior. & QL & Max. & 0 a 5 \\
\hline \multirow{6}{*}{$\mathbf{C 4}$} & \multirow{6}{*}{$\begin{array}{l}\text { Security } \\
\text { aspects }\end{array}$} & 10 & SC4.1 & Fire resistance of exterior envelope materials. & QL & Max. & $0 \mathrm{a} 4$ \\
\hline & & 11 & SC4.2 & Fire resistance of interior envelope materials. & QL & Max. & $0 \mathrm{a} 4$ \\
\hline & & 12 & SC4.3 & Risk to occupants during hurricanes / storms. & QL & $\min$. & 0 a 5 \\
\hline & & 13 & $\mathrm{SC} 4.4$ & Risk to occupants during seismic events. & QL & $\min$. & 0 a 5 \\
\hline & & 14 & $\mathrm{SC} 4.5$ & $\begin{array}{l}\text { Risk to the occupants in case of explosive devices } \\
\text { activation. }\end{array}$ & QL & $\min$. & 0 a 5 \\
\hline & & 15 & SC4.6 & Resistance to hail falling on the roof. & QL & Max. & 0 a 5 \\
\hline \multirow{6}{*}{$\mathrm{C5}$} & \multirow{6}{*}{$\begin{array}{l}\text { Constructive } \\
\text { aspects }\end{array}$} & 16 & SC5.1 & $\begin{array}{l}\text { Total weight (exterior envelope }+ \text { pavement floor of } \\
\text { extended part). }\end{array}$ & QN & $\min$. & $\mathrm{kg}$ \\
\hline & & 17 & SC5.2 & Ease of installation. & QL & Max. & 0 a 5 \\
\hline & & 18 & SC5.3 & Estimated execution time. & QN & $\min$. & days \\
\hline & & 19 & SC5.4 & $\begin{array}{l}\text { Accessibility for diagnosis / ease of maintenance of exterior } \\
\text { envelope. }\end{array}$ & QL & Max. & 0 a 5 \\
\hline & & 20 & SC5.5 & $\begin{array}{l}\text { Accessibility for diagnosis / ease of maintenance of interior } \\
\text { envelope. }\end{array}$ & QL & Max. & 0 a 5 \\
\hline & & 21 & SC5.6 & $\begin{array}{l}\text { Average durability of outer skin materials of exterior } \\
\text { envelope. }\end{array}$ & QN & $\min$. & years \\
\hline \multirow{5}{*}{ C6 } & \multirow{5}{*}{$\begin{array}{l}\text { Functional } \\
\text { aspects }\end{array}$} & 22 & SC6.1 & Degree of adaptability for future changes & QL & Max. & 0 a 5 \\
\hline & & 23 & SC6.2 & Degree of repeatability. & QL & Max. & 0 a 5 \\
\hline & & 24 & SC6.3 & Degree of reversibility. & QL & Max. & 0 a 5 \\
\hline & & 25 & SC6.4 & Average sound insulation (Rw) of outer envelope. & QN & Max. & $\mathrm{dB}$ \\
\hline & & & SC6.5 & $\begin{array}{l}\text { Total Operational Energy (OE) consumption of the } \\
\text { refurbished building (with vertical extension) ( } 60 \text { years). }\end{array}$ & QN & $\min$. & $\mathrm{KWh}$ \\
\hline \multirow{4}{*}{ C7 } & \multirow{4}{*}{$\begin{array}{l}\text { Environmental } \\
\text { impact aspects }\end{array}$} & & SC7.1 & Total Embodied Energy (EE) in all life cycle (60 years). & QN & $\min$. & MJ \\
\hline & & & SC7.2 & $\begin{array}{l}\text { Total Global Warming Potential (GWP) in all life cycle ( } 60 \\
\text { years). }\end{array}$ & QN & $\min$. & $\mathrm{kgCO} 2 \mathrm{e}$ \\
\hline & & & SC7.3 & $\begin{array}{l}\text { Solid waste generated in construction and maintenance } \\
\text { phases ( } 60 \text { years). }\end{array}$ & QN & $\min$. & $\mathrm{kg}$ \\
\hline & & & SC7.4 & Contribution to local biodiversity. & QL & Max. & 0 a 5 \\
\hline & & & & $\begin{array}{c}\text { LEVEL } 3 \text { - alternatives } \\
\text { CWood; CSteel; AM b; AM v1; AM v2 and AM v3. }\end{array}$ & & & \\
\hline
\end{tabular}

Note: QN - quantitative; QL - qualitative 
Table 2. Measurement of subcriteria - type, scale and description.

\begin{tabular}{|c|c|c|c|}
\hline $\begin{array}{l}\text { Subcriteria } \\
\text { code } \\
\text { (see Table 1) }\end{array}$ & Units/Scale & Type & Description \\
\hline SC1.1 & $€$ & QN & It includes net cost of materials, transport and labour. \\
\hline $\mathrm{SC} 1.2$ & $€$ & QN & $\begin{array}{l}\text { It includes the net cost of energy required for heating } \\
\text { and cooling the extended building part over } 60 \text { years. }\end{array}$ \\
\hline $\mathrm{SC} 1.3$ & $€$ & QN & $\begin{array}{l}\text { It includes the maintenance net cost of exterior } \\
\text { envelope of extended part over } 60 \text { years. }\end{array}$ \\
\hline $\mathrm{SC} 1.4$ & years & QN & $\begin{array}{l}\text { It represents the number of years after which the } \\
\text { vertical extension becomes profitable. }\end{array}$ \\
\hline $\mathrm{SC} 2.1$ & $\begin{array}{l}0 \text { - It does not exist; } 1 \text { - very insufficient; } 2 \text { - } \\
\text { insufficient; } 3 \text { - reasonable; } 4 \text { - good; } 5 \text { - } \\
\text { very good. }\end{array}$ & QL & \\
\hline $\mathrm{SC} 2.2$ & $\begin{array}{l}0 \text { - It does not exist; } 1 \text { - very low; } 2 \text { - low; } 3 \\
\text { - medium; } 4 \text { - high; } 5 \text { - very high. }\end{array}$ & QL & $\begin{array}{l}\text { Is it necessary to vacate the building, completely or in } \\
\text { part, to carry out the extension? }\end{array}$ \\
\hline $\mathrm{SC} 2.3$ & $\begin{array}{l}0 \text { - It does not exist; } 1 \text { - very low; } 2 \text { - low; } 3 \\
\text { - medium; } 4 \text { - high; } 5 \text { - very high. }\end{array}$ & QL & $\begin{array}{l}\text { Intrusiveness: ability to minimize marks or damage to } \\
\text { the asset. }\end{array}$ \\
\hline $\mathrm{SC} 2.4$ & $\begin{array}{l}0 \text { - It does not exist; } 1 \text { - very low; } 2 \text { - low; } 3 \\
\text { - medium; } 4 \text { - high; } 5 \text { - very high. }\end{array}$ & QL & $\begin{array}{l}\text { Noise, dust, temporary obstruction of the public road, } \\
\text { arising from the vertical extension construction phase. }\end{array}$ \\
\hline $\mathrm{SC} 3.1$ & $\begin{array}{c}0 \text { - It does not exist; } 1 \text { - very insufficient; } 2 \text { - } \\
\text { insufficient; } 3 \text { - reasonable; } 4 \text { - good; } 5 \text { - } \\
\text { very good. }\end{array}$ & QL & $\begin{array}{l}\text { Scale, colour and form. Regarding existing building and } \\
\text { its immediate surroundings. The visual impact should } \\
\text { be low. The aesthetic quality is reflected in the degree } \\
\text { of integration between new and the existing elements - } \\
\text { harmony of the set - and the visual impact of new } \\
\text { elements. }\end{array}$ \\
\hline SC4.1 & $\begin{array}{l}0 \text { - It does not comply with legal } \\
\text { requirements; } 1 \text { - E; } 2 \text { - B, C or D; } 3 \text { - A2: } \\
\text { combustible; } 4 \text { - A1: non-combustible. }\end{array}$ & QL & \\
\hline $\mathrm{SC} 4.2$ & $\begin{array}{l}0 \text { - It does not comply with legal } \\
\text { requirements; } 1 \text { - E; } 2 \text { - } \mathrm{B}, \mathrm{C} \text { or } \mathrm{D} ; 3 \text { - } \mathrm{A} 2 \text { : } \\
\text { combustible; } 4 \text { - A1: non-combustible. }\end{array}$ & QL & \\
\hline $\mathrm{SC} 4.3$ & $\begin{array}{l}0 \text { - It does not exist; } 1 \text { - very low; } 2 \text { - low; } 3 \\
\text { - medium; } 4 \text { - high; } 5 \text { - very high. }\end{array}$ & QL & \multirow{3}{*}{$\begin{array}{l}\text { What is the risk to the occupants resulting from the } \\
\text { implementation of each alternative option, regarding } \\
\text { each event (seismic, storms, etc.). That is, to what } \\
\text { extent each alternative may present increased risks to } \\
\text { the occupant lives when risk events occur; there should } \\
\text { be no out of plane material projection, dripping or } \\
\text { uplift, etc. }\end{array}$} \\
\hline $\mathrm{SC} 4.4$ & $\begin{array}{l}0 \text { - It does not exist; } 1 \text { - very low; 2- low; 3- } \\
\text { medium; 4- high; 5- very high. }\end{array}$ & QL & \\
\hline $\mathrm{SC} 4.5$ & $\begin{array}{l}0 \text { - It does not exist; } 1 \text { - very low; } 2 \text { - low; } 3 \text { - } \\
\text { medium; 4- high; 5- very high. }\end{array}$ & QL & \\
\hline SC4.6 & $\begin{array}{c}0 \text { - It does not exist; } 1 \text { - very insufficient; } 2 \text { - } \\
\text { insufficient; } 3 \text { - reasonable; } 4 \text { - good; } 5 \text { - } \\
\text { very good. }\end{array}$ & QL & $\begin{array}{l}\text { In the case of membrane surfaces, deformation caused } \\
\text { by hail falling is recoverable over time through surface } \\
\text { heating. In the case of glass, ceramic or metallic } \\
\text { surfaces, deformation or cracking are only recoverable } \\
\text { with repair works. }\end{array}$ \\
\hline SC5.1 & $\mathrm{kg}$ & QN & \\
\hline SC5.2 & $\begin{array}{c}0 \text { - impossible; } 1 \text { - very difficult; } 2 \text { - } \\
\text { difficult; } 3 \text { - reasonably; } 4 \text { - easy; } 5 \text { - very } \\
\text { easy. }\end{array}$ & QL & Installation should be quick, clean and safe. \\
\hline SC5.3 & days & QN & $\begin{array}{l}\text { It has repercussions in the exposure time of building } \\
\text { parts to adverse climatic actions during refurbishment } \\
\text { works, especially in cases where it is necessary to } \\
\text { remove the original roof (as in this case study). }\end{array}$ \\
\hline SC5.4 & $\begin{array}{l}0 \text { - It does not exist; } 1 \text { - very insufficient; } 2 \text { - } \\
\text { insufficient; } 3 \text { - reasonable; } 4 \text { - good; } 5 \text { - } \\
\text { very good. }\end{array}$ & QL & \\
\hline SC5.5 & $\begin{array}{l}0 \text { - It does not exist; } 1 \text { - very insufficient; } 2 \text { - } \\
\text { insufficient; } 3 \text { - reasonable; } 4 \text { - good; } 5 \text { - } \\
\text { very good. }\end{array}$ & QL & \\
\hline SC5.6 & years & $\mathrm{QN}$ & \\
\hline SC6.1 & $\begin{array}{l}0 \text { - It does not exist; } 1 \text { - very low; } 2 \text { - low; } 3 \\
\text { - medium; } 4 \text { - high; } 5 \text { - very high. }\end{array}$ & QL & $\begin{array}{l}\text { Changes can be formal, concerning functional upgrades } \\
\text { of materials/ components, etc. Removal/extension } \\
\text { potential of added building elements in the future. }\end{array}$ \\
\hline SC6.2 & $\begin{array}{l}0 \text { - It does not exist; } 1 \text { - very low; } 2 \text { - low; } 3 \\
\text { - medium; } 4 \text { - high; } 5 \text { - very high. }\end{array}$ & QL & $\begin{array}{l}\text { Repeatability: ability to disassemble and assemble the } \\
\text { constructive solution in another place. }\end{array}$ \\
\hline SC6.3 & $\begin{array}{l}0 \text { - It does not exist; } 1 \text { - very low; } 2 \text { - low; } 3 \\
\text { - medium; } 4 \text { - high; } 5 \text { - very high. }\end{array}$ & QL & $\begin{array}{l}\text { Reversibility: total or partial replacement capacity of } \\
\text { the building solution components under analysis. }\end{array}$ \\
\hline SC6.4 & $\mathrm{dB}$ & QN & \\
\hline SC6.5 & $\mathrm{kWh}$ & QN & \\
\hline SC7.1 & MJ & QN & \\
\hline SC7.2 & $\mathrm{kgCO}_{2} \mathrm{e}$ & QN & \\
\hline SC7.3 & $\mathrm{kg}$ & QN & \\
\hline
\end{tabular}


Table 3: Baseline decision-making scenario - weight assignment results to each criterion and sub criterion.

\begin{tabular}{|c|c|c|c|c|c|c|c|}
\hline No & $\begin{array}{l}\text { Weigh } \\
\text { t }\end{array}$ & Criteria & $\begin{array}{c}\text { No } \\
\cdot\end{array}$ & Code & $\begin{array}{c}\text { Local } \\
\text { Weigh } \\
t\end{array}$ & $\begin{array}{c}\text { Global } \\
\text { Weigh } \\
t\end{array}$ & Subcriteria \\
\hline \multirow{4}{*}{ C1 } & \multirow{4}{*}{$15 \%$} & \multirow{4}{*}{$\begin{array}{l}\text { Economic } \\
\text { aspects }\end{array}$} & 1 & SC1.1 & $30 \%$ & $5 \%$ & Construction cost. \\
\hline & & & 2 & $\mathrm{SC1} 1.2$ & $30 \%$ & $5 \%$ & Operational energy cost (heating and cooling for 60 years). \\
\hline & & & 3 & SC1.3 & $30 \%$ & $5 \%$ & Maintenance cost (60 years). \\
\hline & & & 4 & SC1.4 & $10 \%$ & $2 \%$ & Payback period of investment in vertical extension design option. \\
\hline \multirow{4}{*}{$\mathrm{C} 2$} & \multirow{4}{*}{$8 \%$} & \multirow{4}{*}{$\begin{array}{l}\text { Social, } \\
\text { cultural and } \\
\text { patrimonial } \\
\text { aspects }\end{array}$} & 5 & SC2.1 & $25 \%$ & $2 \%$ & Use of traditional building materials and techniques. \\
\hline & & & 6 & SC2.2 & $11 \%$ & $1 \%$ & Ability to install in occupied sites. \\
\hline & & & 7 & $\mathrm{SC} 2.3$ & $52 \%$ & $4 \%$ & Degree of intrusiveness. \\
\hline & & & 8 & SC2.4 & $12 \%$ & $1 \%$ & Impact of the constructive process on the neighbourhood. \\
\hline C3 & $7 \%$ & $\begin{array}{l}\text { Aesthetic } \\
\text { aspects }\end{array}$ & 9 & $\mathrm{SC} 3.1$ & $100 \%$ & $7 \%$ & Aesthetic quality of intervention form exterior. \\
\hline \multirow{6}{*}{$\mathbf{C 4}$} & \multirow{6}{*}{$22 \%$} & \multirow{6}{*}{$\begin{array}{l}\text { Security } \\
\text { aspects }\end{array}$} & 10 & SC4.1 & $10 \%$ & $2 \%$ & Fire resistance of exterior envelope materials. \\
\hline & & & 11 & SC4.2 & $10 \%$ & $2 \%$ & Fire resistance of interior envelope materials. \\
\hline & & & 12 & SC4.3 & $20 \%$ & $4 \%$ & Risk to occupants during hurricanes / storms. \\
\hline & & & 13 & SC4.4 & $20 \%$ & $4 \%$ & Risk to occupants during seismic events. \\
\hline & & & 14 & SC4.5 & $20 \%$ & $4 \%$ & Risk to the occupants in case of explosive devices activation. \\
\hline & & & 15 & SC4.6 & $20 \%$ & $4 \%$ & Resistance to hail falling on the roof. \\
\hline \multirow{6}{*}{ C5 } & \multirow{6}{*}{$12 \%$} & \multirow{6}{*}{$\begin{array}{l}\text { Constructive } \\
\text { aspects }\end{array}$} & 16 & SC5.1 & $45 \%$ & $5 \%$ & $\begin{array}{l}\text { Total weight (exterior envelope }+ \text { pavement floor of extended } \\
\text { part). }\end{array}$ \\
\hline & & & 17 & SC5.2 & $10 \%$ & $1 \%$ & Ease of installation. \\
\hline & & & 18 & SC5.3 & $20 \%$ & $2 \%$ & Estimated execution time. \\
\hline & & & 19 & SC5.4 & $5 \%$ & $1 \%$ & $\begin{array}{l}\text { Accessibility for diagnosis/ease of maintenance of exterior } \\
\text { envelope. }\end{array}$ \\
\hline & & & 20 & SC5.5 & $5 \%$ & $1 \%$ & $\begin{array}{l}\text { Accessibility for diagnosis/ease of maintenance of interior } \\
\text { envelope. }\end{array}$ \\
\hline & & & 21 & SC5.6 & $15 \%$ & $2 \%$ & Average durability of outer skin materials of exterior envelope. \\
\hline \multirow{5}{*}{ C6 } & \multirow{5}{*}{$30 \%$} & \multirow{5}{*}{$\begin{array}{l}\text { Functional } \\
\text { aspects }\end{array}$} & 22 & SC6.1 & $7 \%$ & $2 \%$ & Degree of adaptability for future changes \\
\hline & & & 23 & SC6.2 & $7 \%$ & $2 \%$ & Degree of repeatability. \\
\hline & & & 24 & SC6.3 & $12 \%$ & $4 \%$ & Degree of reversibility. \\
\hline & & & 25 & SC6.4 & $27 \%$ & $8 \%$ & Average sound insulation (Rw) of outer envelope. \\
\hline & & & 26 & SC6.5 & $47 \%$ & $14 \%$ & $\begin{array}{l}\text { Total Operational Energy (OE) consumption of the refurbished } \\
\text { building, (with vertical extension) ( } 60 \text { years). }\end{array}$ \\
\hline \multirow{4}{*}{ C7 } & \multirow{4}{*}{$6 \%$} & \multirow{4}{*}{$\begin{array}{l}\text { Environmenta } \\
\text { l impact } \\
\text { aspects }\end{array}$} & 27 & SC7.1 & $40 \%$ & $2 \%$ & Total Embodied Energy (EE) in all life cycle (60 years). \\
\hline & & & 28 & $\mathrm{SC} 7.2$ & $40 \%$ & $2 \%$ & $\begin{array}{l}\text { Total Global Warming Potential (GWP) in all life cycle ( } 60 \\
\text { years). }\end{array}$ \\
\hline & & & 29 & SC7.3 & $15 \%$ & $1 \%$ & $\begin{array}{l}\text { Solid waste generated in construction and maintenance phases } \\
\text { (60 years). }\end{array}$ \\
\hline & & & 30 & SC7.4 & $5 \%$ & $0,3 \%$ & Contribution to local biodiversity. \\
\hline
\end{tabular}


Table 4: Detailed description of alternatives under analysis: conventional and

membrane building solutions for the rooftop's external envelope.

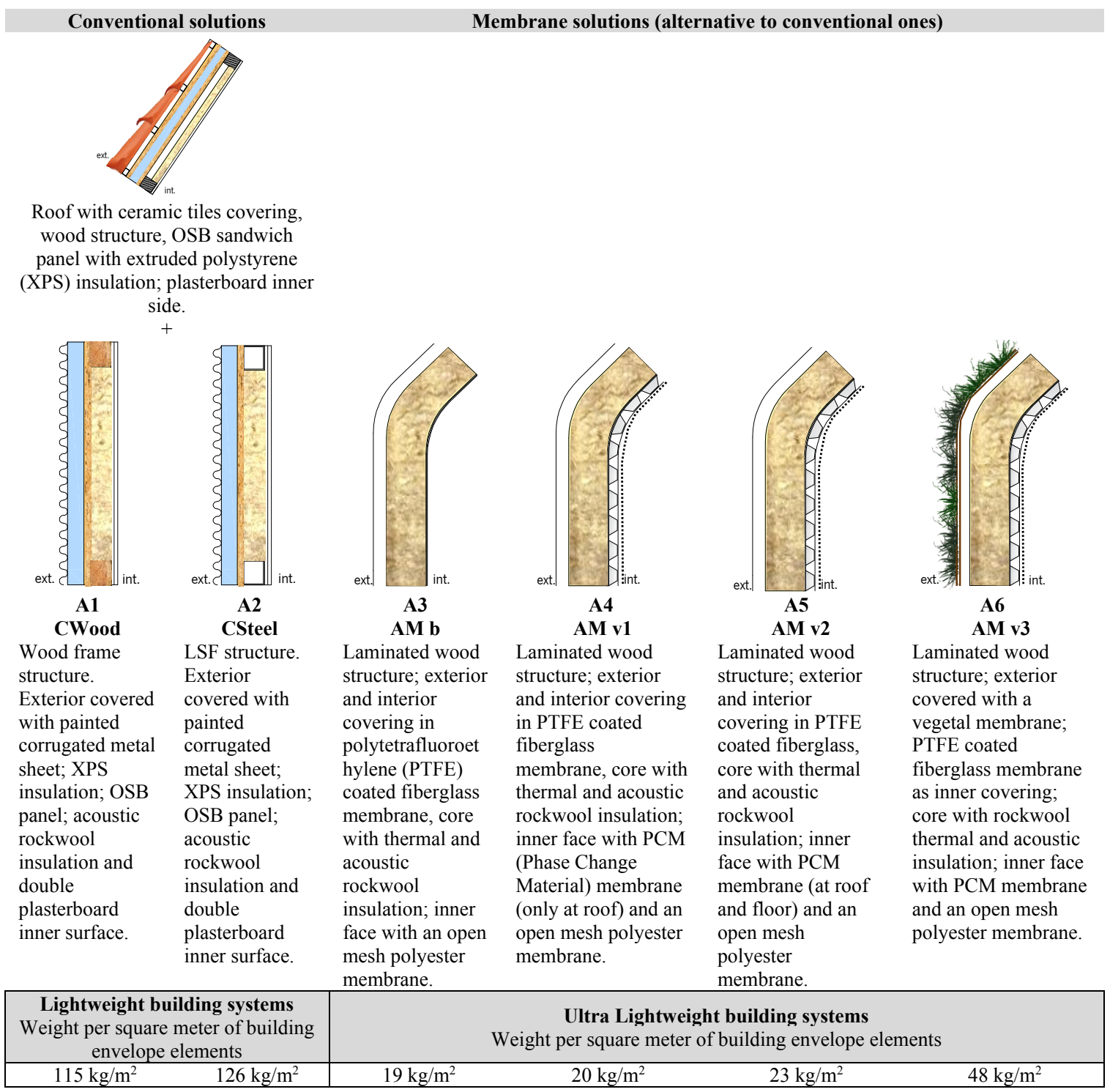


Table 5: Multicriteria evaluation results for each alternative to the Baseline decisionmaking scenario.

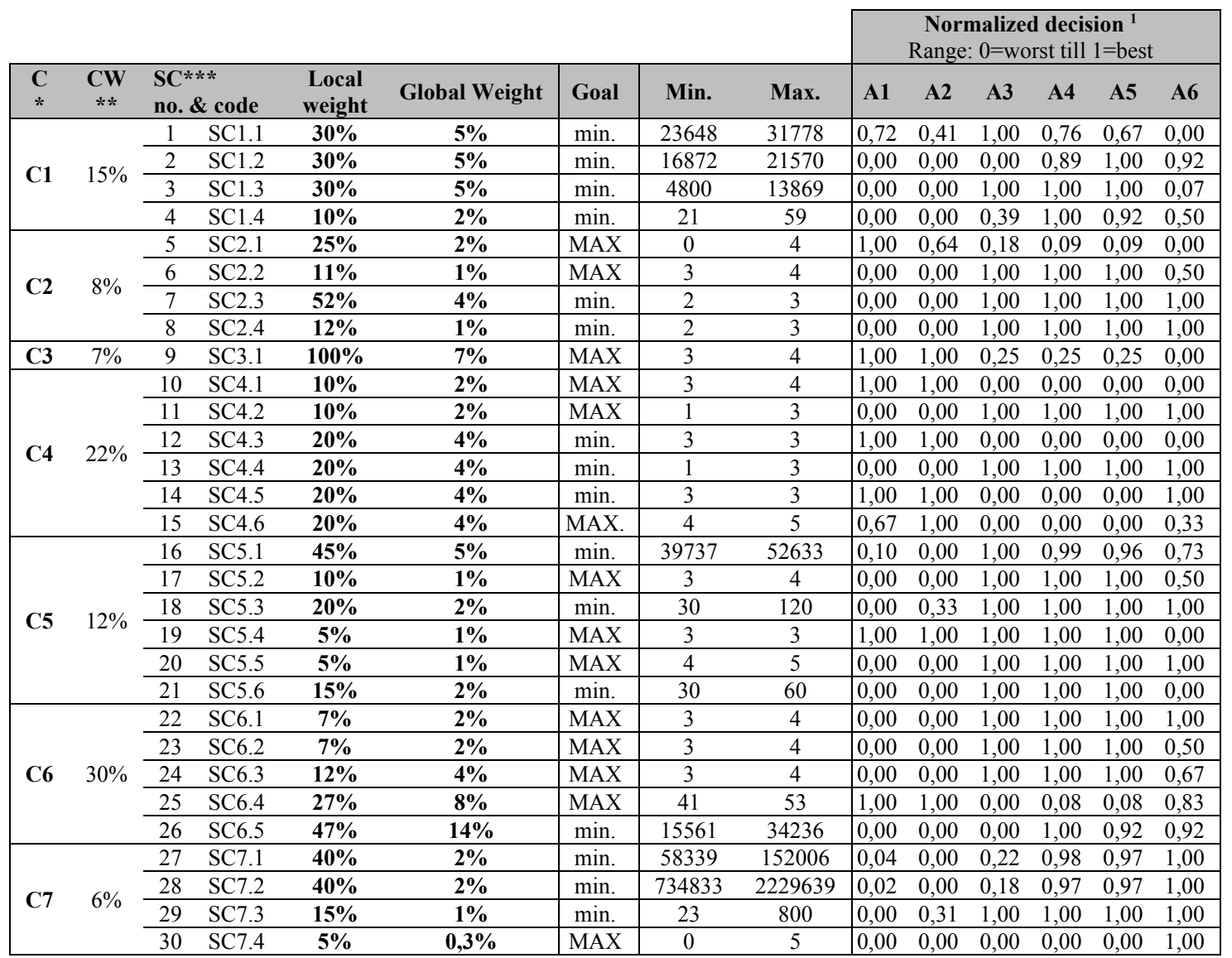

Notes:

*C - Criteria; ** CW - Criteria's weight; *** SC - Sub criteria;

${ }^{1}$ Applied formula to sub criteria values normalization: to maximize: $y=(X-M i n) /(M A X-m i n)$; To minimize: $y=(M A X-X) /(M A X-m i n)$.

Table 6: Considered scenarios for the sensitivity analysis - weight range per criteria.

\begin{tabular}{|c|c|c|c|c|c|c|c|c|}
\hline \multirow{6}{*}{\multicolumn{2}{|c|}{ 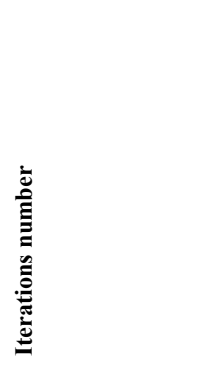 }} & \multicolumn{7}{|c|}{ Weight assignment for each criterion - BASELINE SCENARIO (local group decision makers) } \\
\hline & & $\begin{array}{c}\text { C1 } \\
\text { Economic } \\
\text { aspects }\end{array}$ & $\begin{array}{l}\text { C2 } \\
\text { Social, cultural and } \\
\text { patrimonial aspects }\end{array}$ & $\begin{array}{c}\text { C3 } \\
\text { Aesthetic } \\
\text { aspects }\end{array}$ & $\begin{array}{c}\text { C4 } \\
\text { Security } \\
\text { aspects }\end{array}$ & $\begin{array}{c}\text { C5 } \\
\text { Constructive } \\
\text { aspects }\end{array}$ & $\begin{array}{c}\text { C6 } \\
\text { Functional } \\
\text { aspects }\end{array}$ & $\begin{array}{c}\text { C7 } \\
\text { Environmental } \\
\text { impact aspects }\end{array}$ \\
\hline & & $15 \%$ & $8 \%$ & $7 \%$ & $22 \%$ & $12 \%$ & $30 \%$ & $6 \%$ \\
\hline & & \multicolumn{7}{|c|}{ Weight range cycles } \\
\hline & & \multicolumn{2}{|r|}{ C1 cycle } & \multicolumn{2}{|c|}{ C2 cycle } & \multicolumn{2}{|c|}{ C3 Cycle } & till C7 cycle \\
\hline & & C1 & $\begin{array}{l}\text { Weight per each } \\
\text { remaining criterion } \\
(\text { C2 }- \text { C7) }\end{array}$ & $\mathrm{C} 2$ & $\begin{array}{l}\text { Weight per each } \\
\text { remaining } \\
\text { criterion }(\mathrm{C} 1 \text {; } \\
\text { C3 - C7) }\end{array}$ & C3 & $\begin{array}{l}\text { Weight per } \\
\text { each } \\
\text { remaining } \\
\text { criterion (C1; } \\
\text { C2; C4 - C7) }\end{array}$ & $\ldots \mathrm{C7}$ \\
\hline 1 & Scenario 1 & $0 \%$ & $16,7 \%$ & $0 \%$ & $16,7 \%$ & $0 \%$ & $16,7 \%$ & \\
\hline 2 & Scenario 2 & $10 \%$ & $15,0 \%$ & $10 \%$ & $15,0 \%$ & $10 \%$ & $15,0 \%$ & \\
\hline 3 & Scenario 3 & $20 \%$ & $13,3 \%$ & $20 \%$ & $13,3 \%$ & $20 \%$ & $13,3 \%$ & \\
\hline 4 & Scenario 4 & $30 \%$ & $11,7 \%$ & $30 \%$ & $11,7 \%$ & $30 \%$ & $11,7 \%$ & \\
\hline 5 & Scenario 5 & $40 \%$ & $10,0 \%$ & $40 \%$ & $10,0 \%$ & $40 \%$ & $10,0 \%$ & \\
\hline 6 & Scenario 6 & $50 \%$ & $8,3 \%$ & $50 \%$ & $8,3 \%$ & $50 \%$ & $8,3 \%$ & $\ldots$ \\
\hline 7 & Scenario 7 & $60 \%$ & $6,7 \%$ & $60 \%$ & $6,7 \%$ & $60 \%$ & $6,7 \%$ & \\
\hline 8 & Scenario 8 & $70 \%$ & $5,0 \%$ & $70 \%$ & $5,0 \%$ & $70 \%$ & $5,0 \%$ & \\
\hline 9 & Scenario 9 & $80 \%$ & $3,3 \%$ & $80 \%$ & $3,3 \%$ & $80 \%$ & $3,3 \%$ & \\
\hline 10 & Scenario 10 & $90 \%$ & $1,7 \%$ & $90 \%$ & $1,7 \%$ & $90 \%$ & $1,7 \%$ & \\
\hline 11 & Scenario 11 & $100 \%$ & $0,0 \%$ & $100 \%$ & $0,0 \%$ & $100 \%$ & $0,0 \%$ & \\
\hline
\end{tabular}


Table 7: Sensitivity analysis results - ranking.

\begin{tabular}{|c|cccccc|c|}
\hline \multirow{2}{*}{ Max. } & A1 & A2 & A3 & A4 & A5 & A6 & \multirow{2}{*}{ Min. } \\
& CWood & CSteel & AMb & AMv1 & AMv2 & AMv3 & \\
AMv1 & $53 \%$ & $51 \%$ & $68 \%$ & $100 \%$ & $99 \%$ & $91 \%$ & CSteel \\
\hline
\end{tabular}

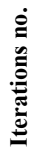

Relative efficiency results - RANGE CYCLES SCENARIOS

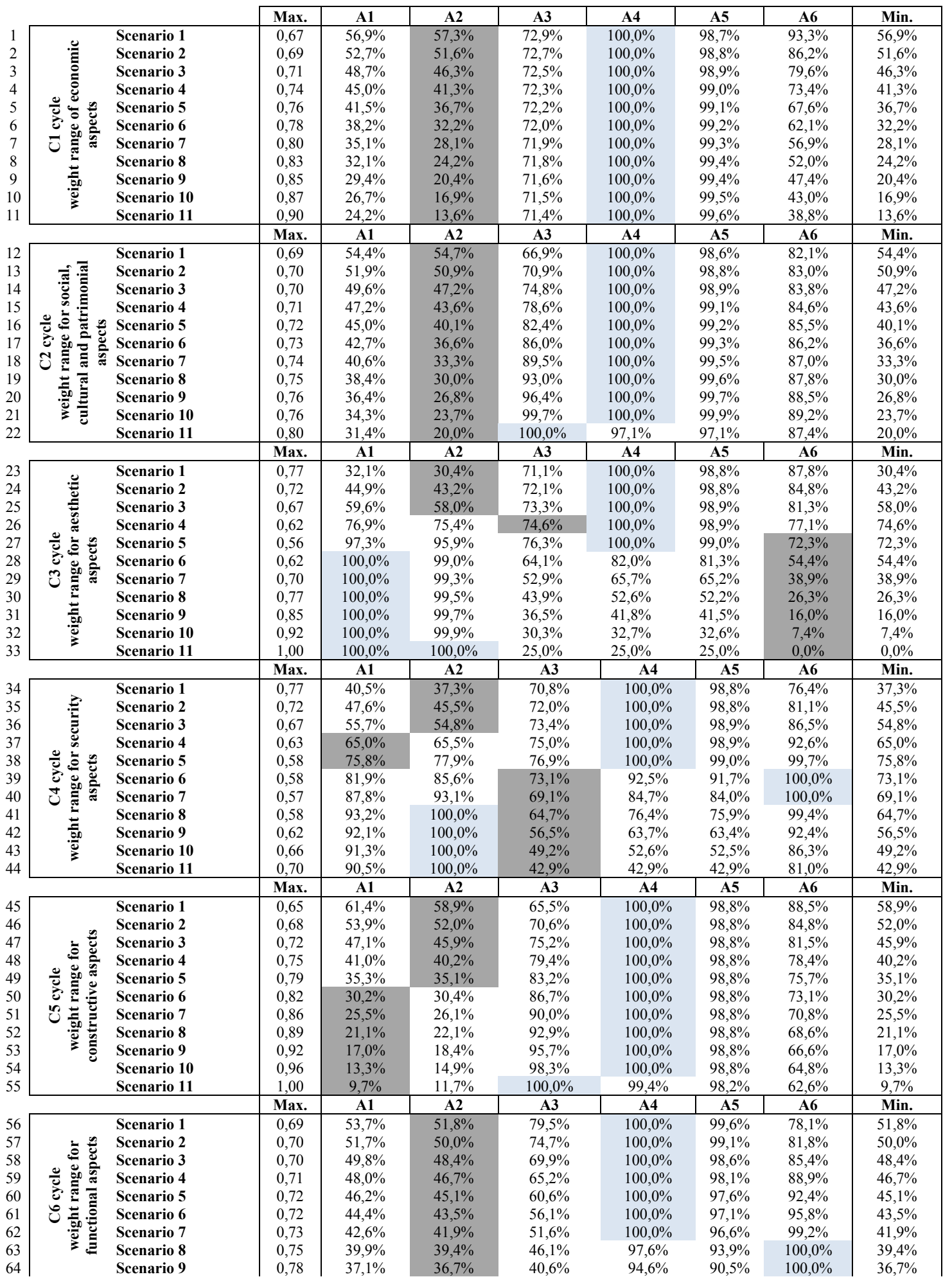




\begin{tabular}{|c|c|c|c|c|c|c|c|c|c|c|}
\hline \multirow{3}{*}{$\begin{array}{l}65 \\
66\end{array}$} & & Scenario 10 & 0,81 & $34,5 \%$ & $34,3 \%$ & $35,5 \%$ & $91,8 \%$ & $87,5 \%$ & $100,0 \%$ & $34,3 \%$ \\
\hline & & Scenario 11 & 0,84 & $32,0 \%$ & $32,0 \%$ & $30,8 \%$ & $89,3 \%$ & $84,6 \%$ & $100,0 \%$ & $30,8 \%$ \\
\hline & & & Max. & A1 & A2 & A3 & A4 & A5 & A6 & Min. \\
\hline 67 & & Scenario 1 & 0,66 & $62,2 \%$ & $59,7 \%$ & $81,9 \%$ & $100,0 \%$ & $98,6 \%$ & $77,7 \%$ & $59,7 \%$ \\
\hline 68 & & Scenario 2 & 0,69 & $54,2 \%$ & $52,3 \%$ & $75,3 \%$ & $100,0 \%$ & $98,8 \%$ & $81,7 \%$ & $52,3 \%$ \\
\hline 69 & ב & Scenario 3 & 0,71 & $46,7 \%$ & $45,5 \%$ & $69,2 \%$ & $100,0 \%$ & $98,9 \%$ & $85,4 \%$ & $45,5 \%$ \\
\hline 70 & $\Xi . \Xi$ & Scenario 4 & 0,74 & $39,8 \%$ & $39,1 \%$ & $63,6 \%$ & $100,0 \%$ & $99,0 \%$ & $88,9 \%$ & $39,1 \%$ \\
\hline 71 & $\cong \Xi$ & Scenario 5 & 0,77 & $33,4 \%$ & $33,2 \%$ & $58,3 \%$ & $100,0 \%$ & $99,2 \%$ & $92,1 \%$ & $33,2 \%$ \\
\hline 72 & 己 & Scenario 6 & 0,80 & $27,4 \%$ & $27,7 \%$ & $53,4 \%$ & $100,0 \%$ & $99,3 \%$ & $95,1 \%$ & $27,4 \%$ \\
\hline 73 & 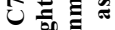 & Scenario 7 & 0,82 & $21,8 \%$ & $22,6 \%$ & $48,9 \%$ & $100,0 \%$ & $99,4 \%$ & $97,9 \%$ & $21,8 \%$ \\
\hline 74 & อ & Scenario 8 & 0,85 & $16,5 \%$ & $17,7 \%$ & $44,3 \%$ & $99,4 \%$ & $98,9 \%$ & $100,0 \%$ & $16,5 \%$ \\
\hline 75 & $=3$ & Scenario 9 & 0,90 & $11,3 \%$ & $12,8 \%$ & $39,4 \%$ & $97,1 \%$ & $96,6 \%$ & $100,0 \%$ & $11,3 \%$ \\
\hline 78 & $\bar{\Phi}$ & Scenario 10 & 0,95 & $6,6 \%$ & $8,5 \%$ & $34,9 \%$ & $94,9 \%$ & $94,6 \%$ & $100,0 \%$ & $6,6 \%$ \\
\hline 7 & & Scenario 11 & 1,00 & $2,5 \%$ & $4,6 \%$ & $30,9 \%$ & $93,0 \%$ & $92,7 \%$ & $100,0 \%$ & $2,5 \%$ \\
\hline
\end{tabular}

\begin{tabular}{|c|c|c|c|c|c|c|}
\hline \multicolumn{7}{|c|}{ Alternatives ranking } \\
\hline & \multicolumn{6}{|c|}{ Efficiency } \\
\hline & A1 & A2 & $\mathbf{A 3}$ & A4 & A5 & A6 \\
\hline & CWood & CSteel & $\mathbf{A M b}$ & AMv1 & AMv2 & AMv3 \\
\hline Average of relative efficiency & $49 \%$ & $48 \%$ & $68 \%$ & $93 \%$ & $92 \%$ & $78 \%$ \\
\hline $\begin{array}{l}\text { Relative average efficiency (from } \\
\text { scenarios set) of each alternative } \\
\text { to the best one }\end{array}$ & $-44 \%$ & $-45 \%$ & $-25 \%$ & $0 \%$ & $-1 \%$ & $-15 \%$ \\
\hline Efficiency ranking $\left(1^{\text {st }}\right.$ best $)$ & $5^{\text {th }}$ & $6^{\text {th }}$ & $4^{\text {th }}$ & $1^{\text {st }}$ & $2^{\text {nd }}$ & $3^{\text {rd }}$ \\
\hline
\end{tabular}

